Polymer-supported thioanisole: A versatile

Leave this area blank for abstract info.

platform for organic synthesis reagents

Matthew Kwok Wai Choi and Patrick H. Toy ${ }^{*}$

Department of Chemistry, The University of Hong Kong, Pokfulam Road, Hong Kong, People's Republic of China.
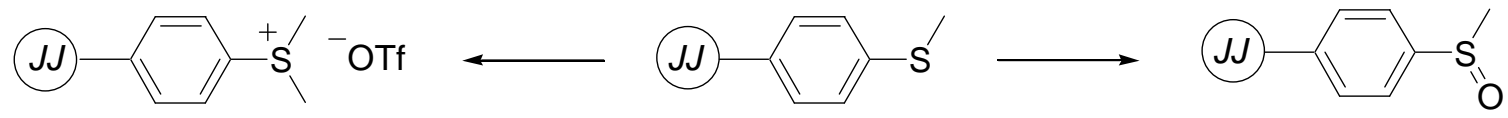


\title{
Polymer-supported thioanisole: A versatile platform for organic synthesis reagents
}

\author{
Matthew Kwok Wai Choi and Patrick H. Toy ${ }^{*}$ \\ Department of Chemistry, The University of Hong Kong, Pokfulam Road, Hong Kong, People’s Republic of China.
}

\begin{abstract}
A new cross-linked polystyrene-supported thioanisole reagent is reported. This reagent incorporates the flexible $J$ andaJel ${ }^{\mathrm{TM}}$ cross-linker and can be treated with methyl trifluoromethanesulfonate to form the corresponding sulfonium salt. This salt can in turn be deprotonated to form a polymer-supported sulfur ylide that is able to react with aldehydes and ketones to form epoxides. The thioanisole reagent can also be oxidized to form an insoluble sulfoxide reagent that is useful in Swern oxidation reactions. In these reactions, the polymer-supported thioanisole-based reagents can be recovered, regenerated and reused. (c) 2008 Elsevier Science. All rights reserved.
\end{abstract}

\section{Introduction}

Recent years have seen polymer-supported reagents and catalysts become common tools for organic synthesis in what is known as polymer-assisted synthesis since they can simplify product isolation and purification. ${ }^{1}$ In this context, both insoluble ${ }^{2}$ and soluble ${ }^{3}$ polymers may be used as the support. The utility and power of such reagents has been exquisitely demonstrated by Ley et al. in their syntheses of several complex natural products using these reagents exclusively. ${ }^{4}$ In order to broaden the range of reactions capable of being performed using such polymer-assisted techniques, new polymer-supported reagents are continually being developed.

As part of our ongoing research into developing such reagents, we have recently reported some non-crosslinked polystyrene-based sulfoxide reagents that are useful in Swern oxidation reactions. ${ }^{5}$ Due to the fact that these polymeric reagents require a precipitation operation prior to their removal from reaction mixtures by filtration, we sought to prepare an insoluble analogous cross-linked reagent so that filtration can be performed directly. We also sought to examine the utility of such a polymer in the sulfide oxidation state by converting it to other organic synthesis reagents. Herein we report our progress in developing an insoluble polymer-supported thioanisole that can be converted into reagents for oxidation and epoxide synthesis reactions.

\section{Results and Discussion}

Previously, cross-linked polymer-supported thioanisole has been prepared by bromination of preformed polystyrene beads followed by lithiation and trapping of the resulting aryl lithium intermediate with dimethyl disulfide. ${ }^{6,7}$ Since this procedure requires a sequence of 3 reactions that must proceed predictably in high yield with no side products being formed in order to obtain a homogeneous polymer-supported reagent, we chose to incorporate the sulfide moieties into our reagent by using a functional styrene monomer ${ }^{8}$ in the polymerization process. Using this strategy allows for the direct preparation of a maximally loaded and homogeneous reagent in which all of the non-cross-linker aryl rings are derivatized with the desired methyl sulfide groups. This is the method that we previously employed in the development of the JandaJel ${ }^{\mathrm{TM}}$ polystyrene resins ${ }^{9,10}$ incorporating a variety of functional monomers. ${ }^{11}$

Therefore, we prepared thioanisole monomer $\mathbf{1}$ according to the literature procedure from 4-bromostyrene (Scheme 1). ${ }^{12}$ This was suspension co-polymerized ${ }^{13}$ with 2 mole percent of the flexible JandaJel ${ }^{\mathrm{TM}}$ cross-linker to afford polymer-supported thioanisole 2 (JandaJel ${ }^{\mathrm{TM}}-\mathrm{SMe}$ ). By preparing reagent $\mathbf{2}$ in this manner, the loading level (5.9 $\mathrm{mmol} / \mathrm{g}$ ) could be maximized and thereby reducing the amounts of polymeric reagent and solvent necessary for performing the subsequent reactions.

\footnotetext{
* Corresponding author. Tel.: +852-2859-2167; fax: +852-2857-1586; e-mail: phtoy@hkucc.hku.hk.
} 
Scheme 1. Synthesis of monomer 1 and polymers 2-4.
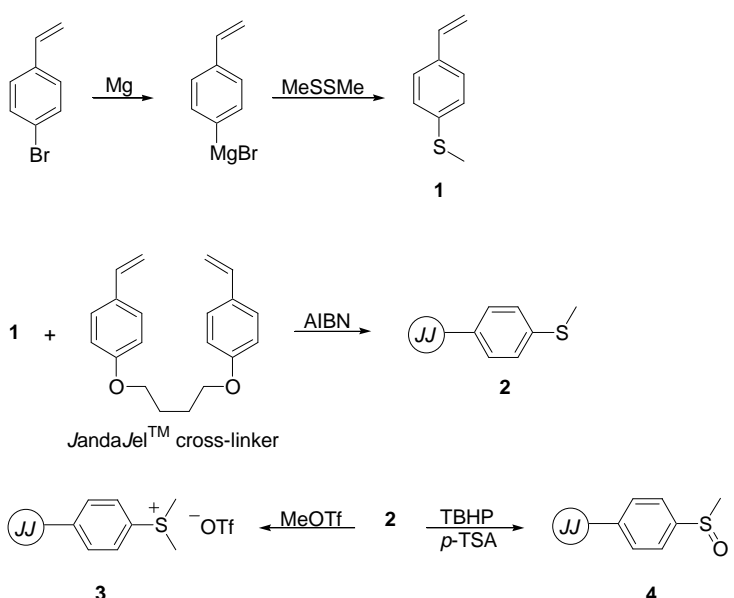

In order to examine the versatility of $\mathbf{2}$ as a platform for sulfur-based organic synthesis reagents, it was treated separately with MeOTf and tert-butyl hydroperoxide (TBHP) in the presence of $p$-TSA to afford sulfonium salt 3 and sulfoxide $\mathbf{4}$, respectively (Scheme 1). Reagent 3 was prepared in order to serve as a polymer-supported precursor to the Corey-Chaykovsky methylide reagent ${ }^{14}$ which can be used to convert carbonyl groups into epoxide moieties. ${ }^{7,15,16}$ Reagent $\mathbf{4}$ was prepared to serve as a polymer-supported analog of dimethyl sulfoxide for use in Swern oxidation reactions. ${ }^{17}$

Reagent 3 was deprotonated with sodium hydride under conditions similar to those reported by Fréchet et al. ${ }^{7}$ for deprotonation of sulfonium salts using potassium tertbutoxide, and the resulting ylide was allowed to react with a range of aldehydes and ketones to afford the corresponding epoxides (Table 1). In all cases, the starting carbonyl compound was completely consumed and product was isolated in good to excellent yield. In the reaction of the ylide from 3 with trans-cinnamaldehyde, only 1,2-addition was observed (Table 1, entry 5). Furthermore, reactions with ketones afforded slightly higher yields (Table 1, entries 6-8) than did reactions with aldehydes (Table 1 , entries 1-5).

In order to examine the recyclability of the polymer recovered from the epoxide synthesis reactions, the reaction represented in Table 1 , entry 6 was performed 5 times using the same sample of $\mathbf{3}$. Since $\mathbf{3}$ was used as the excess reagent in these reactions, the polymer recovered at the end of the reaction was a mixture of $\mathbf{2}$ and 3. Therefore, at the end of each reaction cycle, the polymer was recovered, washed and reacted with MeOTf in order to convert it to pure 3 . This was then reused for epoxide formation in a total of 5 cycles (Table 2). As can be seen, essentially identical yields were observed for each reaction, clearly indicating that $\mathbf{3}$ can be regenerated and reused without any decrease in effectiveness.
Table 1. Epoxide synthesis reactions using 3.

Entry Yield (\%)

Table 2. Yields of 2-(4-bromophenyl)-2-methyloxirane from 4'-bromoacetophenone using recycled 3.

\begin{tabular}{cc}
\hline Cycle Number & Yield (\%) \\
\hline 1 & 98 \\
2 & 97 \\
3 & 99 \\
4 & 98 \\
5 & 97
\end{tabular}

Swern oxidation reactions using polymer 4 were examined next. A cross-linked polystyrene-based sulfoxide polymer related to $\mathbf{4}$ has been previously used in triphasic catalysis, ${ }^{18}$ and in alcohol oxidation reactions involving chlorine activation. ${ }^{6} \quad$ Additionally, other polymer-supported sulfoxide reagents have been used previously in Swern oxidation reactions. ${ }^{19,20}$ However, these reagents required multi-step synthesis to produce polymers that were not maximally functionalized with 
sulfoxide moieties, as is $\mathbf{4}$. Therefore, $\mathbf{4}$ should be more efficient to use since the nature of its functionalization is known precisely and its relatively higher concentration of sulfoxide moieties means that less reagent and solvent are required for the oxidation reactions.

A variety of secondary alcohols were oxidized using excess $\mathbf{4}$ and oxalyl chloride. The results of these reactions are summarized in Table 3 . In these reactions, the starting material was completely consumed and the yield reported represents isolated product. In all cases, the desired product could be isolated in essentially pure form from the reaction mixture in satisfactory yield after several filtration operations.

To assess the reusability of the polymer recovered from the oxidation reactions, the reaction represented in Table 3 , entry 1 was performed 5 times using the same sample of 4 . Since the polymer recovered at the end of the reaction was a mixture of $\mathbf{2}$ and $\mathbf{4}$, the sample was reoxidized with TBHP and $p$-TSA to regenerate homogeneous 4. As can be seen in Table 4, only a modest decrease in product yield was observed in each subsequent cycle. Regardless of this, the results are acceptable because in each case the product was isolated in a pure state, and in polymer-assisted synthesis, generally product yield is of secondary importance to product purity.

Table 3. Swern oxidation reactions using reagent 4.

Entry Yield (\%)

Table 4. Yields of 4'-bromoacetophenone from 1-(4bromophenyl)ethanol oxidation using recycled 4.

\begin{tabular}{cc}
\hline Cycle Number & Yield (\%) \\
\hline 1 & 80 \\
2 & 76 \\
3 & 70 \\
4 & 67 \\
5 & 65
\end{tabular}

\section{Conclusions}

In summary, we have developed a cross-linked polymersupported thioanisole platform (2) that can serve as a foundation for the preparation various sulfur-based reagents for organic synthesis. We have used 2 to prepare a precursor of a sulfur ylide (3) and a sulfoxide (4) for oxidation reaction. These reagents can be used repeatedly with only modest decrease in their effectiveness. Furthermore, it is expected that $\mathbf{2}$ can serve as the starting material for additional polymer-supported reagents and studies directed at developing these are currently underway.

\section{Experimental}

4.1. General. All reagents were obtained from the Aldrich, Lancaster or Acros chemical companies and were used without further purification. All moisture sensitive reactions were carried out in dried glassware under a $\mathrm{N}_{2}$ atmosphere. Tetrahydrofuran was distilled under a $\mathrm{N}_{2}$ atmosphere over sodium and benzophenone. Dichloromethane and dimethyl sulfoxide were distilled under a $\mathrm{N}_{2}$ atmosphere and in vacuo, respectively, over calcium hydride. Merck silica gel 60 (230-400 mesh) was used for chromatography. Thin layer chromatography analysis was performed using glass plates coated with silica gel $60 \mathrm{~F}_{254}$. The NMR spectra were recorded using a Bruker DRX 400 spectrometer. Chemical shift data is expressed in ppm with reference to TMS. EI-MS data was recorded on a Finnigan MAT 96 mass spectrometer. Elemental analyses were conducted at the Analytical and Testing Center of the Shanghai Institute of Organic Chemistry.

4.2. 4-Vinylphenyl methyl sulfide (1). Methyl disulfide (21.6 g, $229.0 \mathrm{mmol})$ was added slowly at $0{ }^{\circ} \mathrm{C}$ to a solution of the Grignard reagent prepared from 4bromostyrene (28.0 g, $153.0 \mathrm{mmol})$ and $\mathrm{Mg}$ (7.4 g, 305.0 $\mathrm{mmol})$ in dry THF (200 mL). The mixture was stirred at room temperature for $3 \mathrm{~h}$. At this time, the reaction mixture was diluted with diethyl ether $(500 \mathrm{~mL})$, and then washed sequentially with water ( $250 \mathrm{~mL}), 10 \%$ aqueous $\mathrm{HCl}(250 \mathrm{~mL})$, saturated aqueous $\mathrm{NaHCO}_{3}(250 \mathrm{~mL})$ and brine $(250 \mathrm{~mL})$. The organic layer was dried over $\mathrm{MgSO}_{4}$, filtered and concentrated in vacuo. The crude product was purified by silica gel chromatography (5\% 
EtOAc/hexanes) to afford $\mathbf{1}$ as a clear, colorless liquid (16.0 g, 106.5 mmol, 70\%). ${ }^{1} \mathrm{H}$ NMR (400 MHz, $\mathrm{CDCl}_{3}$ ) $\delta 2.45$ (s, 3H), 5.21 (dd, $1 \mathrm{H}, J=10.9,0.9 \mathrm{~Hz}$ ), 5.70 (dd, $1 \mathrm{H}, J=17.6,0.9 \mathrm{~Hz}), 6.68$ (dd, $1 \mathrm{H}, J=17.6,10.9 \mathrm{~Hz}$ ), 7.17-7.40 (m, 4H). ${ }^{13} \mathrm{C}$ NMR $\left(100 \mathrm{MHz}, \mathrm{CDCl}_{3}\right) \delta 15.7$, 113.1, 126.6 (4C), 134.5, 136.2, 138.0. HR EI-MS: calcd for $\mathrm{C}_{9} \mathrm{H}_{10} \mathrm{~S}$, 150.0503; found, 150.0500 .

4.3. JandaJel $^{\mathrm{TM}}$-SMe (2). A solution of acacia gum (6.0 g) and $\mathrm{NaCl}(3.8 \mathrm{~g})$ in warm deionized water $\left(45^{\circ} \mathrm{C}, 150\right.$ $\mathrm{mL}$ ) was placed in a $150 \mathrm{~mL}$ flanged reaction vessel equipped with a mechanical stirrer and deoxygenated by purging with $\mathrm{N}_{2}$ for $2 \mathrm{~h}^{21}$ A solution of 1 (10.0 g, 6.7 mmol), cross-linker (0.4 g, $1.5 \mathrm{mmol})$ and AIBN (0.2 g, $1.3 \mathrm{mmol})$ in chlorobenzene $(10 \mathrm{~mL})$ was injected into the rapidly stirred aqueous solution. The mixture was heated at $85{ }^{\circ} \mathrm{C}$ for $20 \mathrm{~h}$. The crude polymer was collected and washed with hot water $(3 \times 100 \mathrm{~mL})$ and then placed in a Soxhlet extractor and washed with THF for one day. The beads were recovered, washed with methanol $(250 \mathrm{~mL})$, diethyl ether $(250 \mathrm{~mL})$, and hexanes $(250 \mathrm{~mL})$. The shrunken beads 2 (9.0 g, 90\%) were dried in vacuo. Elemental analysis was used to determine the sulfur content (18.9\%) and thus the loading level of $5.9 \mathrm{mmol}$ S/g of 2 .

4.4. Janda Jel ${ }^{\mathrm{TM}}-\mathrm{S}(\mathrm{Me})_{2} \mathrm{OTf}$ (3). To a magnetically stirred suspension of 2 (3.0 g, $17.7 \mathrm{mmol})$ in $\mathrm{CH}_{2} \mathrm{Cl}_{2}(30$ $\mathrm{mL}$ ) at rt was added MeOTf (4.4 g, $27.0 \mathrm{mmol})$. Stirring was continued for $24 \mathrm{~h}$ at rt, at which time the resin was filtered off, and washed sequentially with dichloromethane, methanol, diethyl ether, and hexanes. The shrunken beads 3 (6.0 g) were dried in vacuo. Elemental analysis was used to determine the sulfur content (18.3\%) and thus the loading level of $2.9 \mathrm{mmol}$ S/g of 3.

4.5. JandaJel $^{\mathrm{TM}}$-S(O)Me (4). To a magnetically stirred suspension of $2(5.0 \mathrm{~g}, 29.5 \mathrm{mmol})$ in $\mathrm{CH}_{2} \mathrm{Cl}_{2}(40 \mathrm{~mL})$ at rt was added 70\% TBHP (19.3 g, $150.0 \mathrm{mmol}$ ) and $p$-TSA (5.6 g, $30.0 \mathrm{mmol}$ ). Stirring was continued for $24 \mathrm{~h}$ at rt, at which time the resin was filtered off and washed sequentially with dichloromethane, methanol, diethyl ether, and hexanes. The shrunken beads 4 (5.5 g) were dried in vacuo. Elemental analysis was used to determine the sulfur content $(15.4 \%)$ and thus the loading level of $4.8 \mathrm{mmol} \mathrm{S} / \mathrm{g}$ of 4 . Previous reports using this oxidation system indicate that oxidation of the sulfide stops at the sulfoxide oxidation state and that no sulfone is formed. ${ }^{5,18 c}$

4.6. General procedure for epoxide synthesis. A solution of the carbonyl compound $(1.0 \mathrm{mmol})$ in anhydrous DMSO (4 mL) and anhydrous THF (1 mL) was added to a mixture of $3(1.0 \mathrm{~g}, 2.9 \mathrm{mmol})$ and $60 \%$ $\mathrm{NaH}(0.12 \mathrm{~g}, 3.0 \mathrm{mmol})$ in anhydrous THF $(2 \mathrm{~mL})$ that was stirring at $0{ }^{\circ} \mathrm{C}$. The mixture was slowly warmed to room temperature. After the reaction was complete. The suspension was then filter and the resin was washed with addition diethyl ether $(3 \times 10 \mathrm{~mL})$. The combined filtrate was treated with water $(40 \mathrm{~mL})$ and extracted with diethyl ether $(3 \times 20 \mathrm{~mL})$. The combined organic layer was washed with brine $(30 \mathrm{~mL})$, dried over $\mathrm{MgSO}_{4}$, filtered and concentrated in vacuo. The crude residue was filtered through a plug of silica gel to provide the essentially pure epoxide product (Table 1).

4.7. Procedure for regeneration of polymer 3 . The polymer mixture ( 2 with 3 , ca $1.0 \mathrm{~g}$ ) recovered from the epoxide synthesis reaction was treated with MeOTf (1.5 g, $8.9 \mathrm{mmol})$ in $\mathrm{CH}_{2} \mathrm{Cl}_{2}(20 \mathrm{~mL})$ and stirred for $24 \mathrm{~h}$ at rt. The resin was recovered and washed sequentially with dichloromethane, methanol, diethyl ether and hexanes. The shrunken beads 3 were dried in vacuo and reused in the epoxidation reaction. The same sample of $\mathbf{3}$ was used in all 5 cycles reported in Table 2 using this procedure.

4.8. General procedure for alcohol oxidation. A suspension of 4 (1.0 g, $4.8 \mathrm{mmol})$ in anhydrous $\mathrm{CH}_{2} \mathrm{Cl}_{2}$ (30 mL) was cooled to $-70{ }^{\circ} \mathrm{C}$ and oxalyl chloride $(0.6 \mathrm{~g}$, $4.4 \mathrm{mmol}$ ) was added dropwise. After $30 \mathrm{~min}$, a solution of the alcohol $(1.2 \mathrm{mmol})$ in anhydrous $\mathrm{CH}_{2} \mathrm{Cl}_{2}$ was added. The mixture was stirred at low temperature for $1 \mathrm{~h}$ and then triethylamine $(0.7 \mathrm{~g}, 7.2 \mathrm{mmol})$ was added. The solution is kept at $-40{ }^{\circ} \mathrm{C}$ for $1 \mathrm{~h}$ more and then allowed to warm to rt. The suspension was then filtered and the resin was washed with addition $\mathrm{CH}_{2} \mathrm{Cl}_{2}(3 \times 10 \mathrm{~mL})$. The combined filtrate was concentrated in vacuo and the crude residue was filtered through a plug of silica gel to provide the essentially pure oxidation product (Table 3).

4.9. Procedure for regeneration of polymer 4 . The polymer mixture ( 2 with 4 , ca $1.0 \mathrm{~g}$ ) recovered from the oxidation reaction was treated with $70 \%$ TBHP (3.1 g, $24.0 \mathrm{mmol})$ and $p$-TSA $(0.9 \mathrm{~g}, 4.8 \mathrm{mmol})$ in $\mathrm{CH}_{2} \mathrm{Cl}_{2}(20$ $\mathrm{mL}$ ) and stirred at rt for $24 \mathrm{~h}$. The beads were recovered, and washed sequentially with dichloromethane, methanol, diethyl ether and hexanes. The shrunken beads 4 were dried in vacuo and reused in the oxidation reaction. The same sample of $\mathbf{4}$ was used in all 5 cycles reported in Table 4 using this procedure.

\section{Acknowledgments}

This research was supported financially by the University of Hong Kong, and the Research Grants Council of the Hong Kong Special Administrative Region, P. R. of China (Project No. HKU 7112/02P). We also thank Mr. Bob Wandler of the Aldrich Chemical Co. for supplying many of the reagents used in this study.

\section{References}

1. (a) Ley, S. V.; Baxendale, I. R.; Bream, R. N.; Jackson, P. S.; Leach, A. G.; Longbottom, D. A.; Nesi, M.; Scott, J. S.; Storer, R. I.; Taylor, S. J. J. Chem. Soc., Perkin Trans. 1 2000, 3815-4195. (b) Clapham, B.; Reger, T. S.; Janda, K. D. Tetrahedron 2001, 57, 4637-4662.

2. (a) Leadbeater, N. E.; Marco, M. Chem. Rev. 2002, 102, 3217-3274. (b) McNamara, C. A.; Dixon, M. J.; Bradley, 
M. Chem. Rev. 2002, 102, 3275-3300. (c) Fan, Q.-H.; Li, Y.-M.; Chan, A. S. C. Chem. Rev. 2002, 102, 3385-3465.

3. (a) Toy, P. H.; Janda, K. D. Acc. Chem. Res. 2000, 33, 546554. (b) Dickerson, T. J.; Reed, N. N.; Janda, K. D. Chem. Rev. 2002, 102, 3325-3344. (c) Bergbreiter, D. E. Chem. Rev. 2002, 102, 3345-3384

4. (a) Baxendale, I. R.; Ley, S. V.; Nessi, M.; Piutti, C. Tetrahedron 2002, 58, 6285-6304. (b) Bream, R. N.; Ley, S. V.; Procopiou, P. A. Org. Lett. 2002, 4, 3793-3796. (c) Baxendale, I. R.; Ley, S. V.; Piutti, C. Angew. Chem. Int. Ed. 2002, 41, 2194-2197. (d) Storer, R. I.; Takemoto, T.; Jackson, P. S.; Ley, S. V. Angew. Chem. Int. Ed. 2003, 42, 2521-2525.

5. Choi, M. K. W.; Toy, P. H. Tetrahedron 2003, 59, 71717176.

6. Crosby, G. A.; Weinshenker, N. M.; Uh, H.-S. J. Am. Chem. Soc. 1975, 97, 2232-2235.

7. Farrall, M. J.; Durst, T.; Fréchet, J. M. J. Tetrahedron Lett. 1979, 20, 203-206.

8. Arshady, R. J. Macromol. Sci. Rev. Macromol. Chem. Phys. 1992, C32, 101-132.

9. (a) Toy, P. H.; Janda, K. D. Tetrahedron Lett. 1999, 40, 6329-6332. (b) Toy, P. H.; Reger, T. S.; Janda, K. D. Aldrichimica Acta 2000, 33, 87-93. (c) Toy, P. H.; Reger, T. S.; Garibay, P.; Garno, J. C.; Malikayil, J. A.; Liu, G.-Y.; Janda, K. D. J. Comb. Chem. 2001, 3, 117-124.

10. JandaJel is a registered trademark of the Aldrich Chemical Co.

11. (a) Garibay, P.; Toy, P. H.; Hoeg-Jensen, T.; Janda, K. D. Synlett 1999, 1438-1440. (b) Toy, P. H.; Reger, T. S.; Janda, K. D. Org. Lett. 2000, 2, 2205-2207. (c) Manzotti, R.; Reger, T. S. Janda, K. D. Tetrahedron Lett. 2000, 41, 84178420. (d) Lee, S.-H.; Clapham, B.; Koch, G.; Zimmermann, J.; Janda, K. D. J. Comb. Chem. 2003, 5, 188-196. (e) Choi,
M. K. W.; He, H. S.; Toy, P. H. J. Org. Chem. 2003, 68, 9831-9834.

12. Hirao, A.; Shione, H.; Ishizone, T.; Nakahama, S. Macromolecules 1997, 30, 3728-3731.

13. (a) Arshady, R. Colloid Polym. Sci. 1992, 270, 717-732. (b) Sherrington, D. C. Chem. Commun. 1998, 2275-2286.

14. (a) Corey, E. J.; Chaykovsky, M. J. Am. Chem. Soc. 1962, 84, 3782-3783. (b) Corey, E. J.; Chaykovsky, M. J. Am. Chem. Soc. 1965, 87, 1353-1364. (c) Gololobov, Y. G.; Nesmeyanov, A. N.; Lysenko, V. P.; Boldeskul, I. E. Tetrahedron 1987, 43, 2609-2651.

15. (a) Forbes, D. C.; Standen, M. C.; Lewis, D. L. Org. Lett. 2003, 5, 2283-2286. (b) Ciaccio, J. A.; Drahus, A. L.; Meis, R. M.; Tingle, C. T.; Smrtka, M.; Geneste, R. Synth. Commun. 2003, 33, 2135-2143.

16. For a report of other polymer-supported sulfur ylides used to prepare cyclopropanes and epoxides, see: La Porta, E.; Piarulli, U.; Cardullo, F.; Paio, A.; Provera, S.; Seneci, P.; Gennari, C. Tetrahedron Lett. 2002, 43, 761-766.

17. (a) Mancuso, A. J.; Swern, D. Synthesis 1981, 165-185. (b) Tidwell, T. T. Synthesis 1990, 857-870.

18. Kondo, S.; Yasui, H.; Tsuda, K. Makromol. Chem. 1989, 190, 2079-2089.

19. (a) Liu, Y.; Vederas, J. C. J. Org. Chem. 1996, 61, 78567859. (b) Harris, J. M.; Liu, Y.; Chai, S.; Andrews, M. D.; Vederas, J. C. J. Org. Chem. 1998, 63, 2407-2409. (c) Cole, D. C.; Stock, J. R.; Kappel, J. A. Bioorg. Med. Chem. Lett. 2002, 12, 1791-1793.

21. For fluorous Swern oxidation reactions, see: (a) Crich, D.; Neelamkavil, S. J. Am. Chem. Soc. 2001, 123, 7449-7450. (b) Crich, D.; Neelamkavil, S. Tetrahedron 2002, 58, 38653870 .

20. For details of the apparatus used, see: Wilson, M. E.; Paech, K.; Zhou, W. J.; Kurth, M. J. J. Org. Chem. 1998, 63, 50945099. 